\title{
Advanced Method for Magnetic Microwires Noise Specification
}

\author{
D. PrasličKa*, M. Šmelko, J. BlažEk, J. Hudák, P. Lipovský and N. Flachbart \\ Department of Aviation Technical Studies, Faculty of Aeronautics, Technical University of Košice, \\ Rampová 7, 04121 Košice, Slovakia
}

\begin{abstract}
The article points to the effects of the ambient noise and its possible influences on quantification of the inherent switching field noise of magnetic microwires. Based on the observed effects, an advanced methodology was developed to quantify the impact of the ambient noise. During measurements a multi-channel system with applied correlation methods was used. The proposed method determines the percentage contribution of the ambient noise deviation to the magnetic microwires switching field noise.
\end{abstract}

DOI: 10.12693 /APhysPolA.126.86

PACS: $75.50 . \mathrm{Kj}, 85.75 . \mathrm{Ss}$

\section{Introduction}

Magnetic measurements are nowadays more and more influenced by ambient electromagnetic noise. There are many sources of ambient noise and they vary from power line noise, radio-frequency noise, vibrations, geomagnetic and atmospheric phenomena etc. This noise, deterministic and stochastic, can distort the precise measurement either partially or even completely.

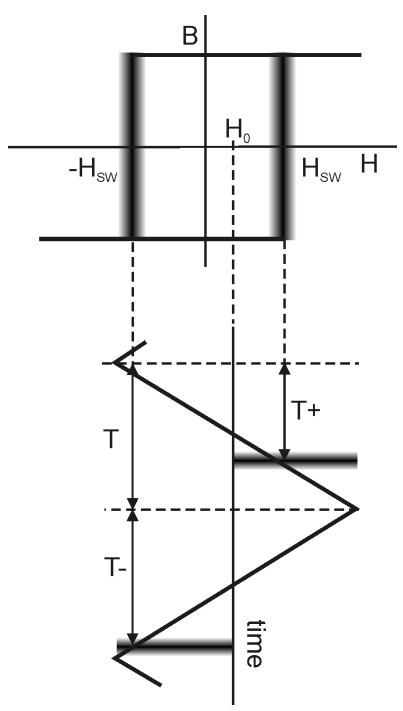

Fig. 1. Fundamental principle of induction method.

\section{Measurement of switching field $H_{S W}$}

Switching field of the magnetic microwires is a carrier of information about several physical quantities such as external magnetic field, tensile stress, temperature and

\footnotetext{
*corresponding author; e-mail: dusan.praslicka@tuke.sk
}

so on. It can be measured by simple induction method based on precise measurement of time [1]. Fundamental principle is presented in Fig. 1.

Tested microwire is placed in the excitation field of triangular shape with amplitude $H_{M A X}$. Changes of the microwire magnetic state are indicated by the voltage peaks, inducted in the sensing coil. The primary carrier of information about the switching field and related properties are the time values $T^{+}$and $T^{-}$, as is evident from the Fig. 1. One can derive the following equations (1) and (2), which create two series of samples $X^{+}$and $X^{-}$, as a result of the excitation field slope.

$$
\begin{aligned}
& x_{i}^{+}=\frac{2 T_{i}^{+}}{T} \bar{H}_{M A X}=\left(H_{S W}\right)_{i}+\left(H_{M A X}\right)_{i}-\left(H_{0}\right)_{i} ; \\
& x_{i}^{-}=\frac{2 T_{i}^{-}}{T} \bar{H}_{M A X}=\left(H_{S W}\right)_{i}+\left(H_{M A X}\right)_{i}+\left(H_{0}\right)_{i} ;
\end{aligned}
$$

The mean values of ambient magnetic field and microwire switching field could be simultaneously derived by subtraction and summation of equations (1) and (2).

$$
\begin{aligned}
& \bar{H}_{0}=-\frac{1}{2 N} \sum_{i=1}^{N}\left(x_{i}^{+}-x_{i}^{-}\right) \\
& \bar{H}_{S W}=\frac{1}{2 N} \sum_{i=1}^{N}\left(x_{i}^{+}+x_{i}^{-}\right)-\bar{H}_{M A X} ;
\end{aligned}
$$

From this brief explanation one can easily realize how easy it is to get values of $H_{S W}$ and $H_{0}$ in direct digital form and construct micro sensors of various physical quantities. Noise of $H_{S W}$ is then the limiting factor of the reliability [2]. It is still a challenge for the manufacturers of microwires to make them defect free, with optimal chemical composition and reproducible.

\section{Inherent noise of switching field $H_{S W}$}

In Fig. 2. a series of $X^{+}$samples are shown, where the noise of the measurement is evident. This noise is given by superposition of the ambient noise $\left(H_{0}, H_{M A X}\right)$ and the inherent noise $\left(H_{S W}\right)$ of microwire. 


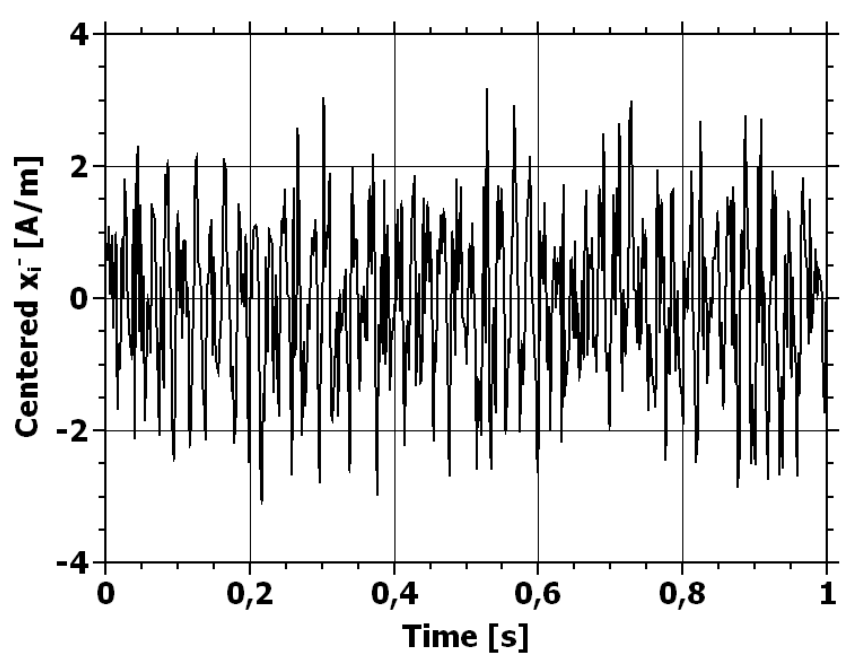

Fig. 2. Noise of $\mathrm{X}$ samples series.

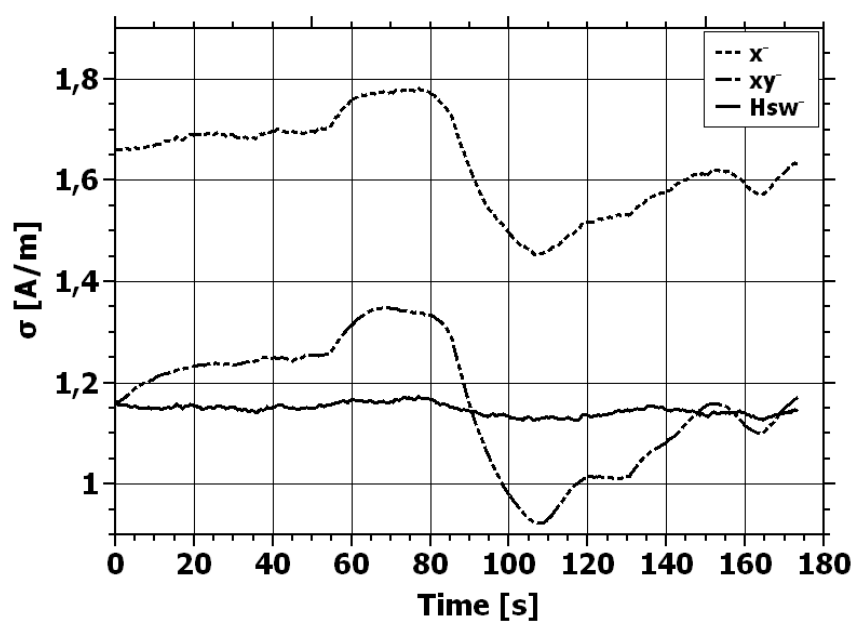

Fig. 3. Time dependence of standard deviation of measured and corrected $\mathrm{H}_{S W}$.

The variance of the $X^{+}$samples series is given by next equation

$$
\operatorname{var}\left(X^{+}\right)=\sigma_{X+}^{2}=\frac{1}{N} \sum_{i=1}^{N}\left(x_{i}^{+}-\bar{X}^{+}\right)^{2} .
$$

This variance includes all kind of noises, ambient and inherent. To separate this kind of noises and to specify exactly the noise of $H_{S W}$, we either need a high quality shielding chamber or to use a two channel system and measure simultaneously two microwires. The microwires have to be placed in parallel, not too far from each other, in order to be in the same ambient field and not too close in order to minimize the interference. The variance of the second channel $Y$ is given by equation

$$
\operatorname{var}\left(Y^{+}\right)=\sigma_{Y+}^{2}=\frac{1}{N} \sum_{i=1}^{N}\left(y_{i}^{+}-\bar{Y}^{+}\right)^{2} .
$$

Now we can calculate the covariance of the channels $X$ and $Y$, which represents the power of ambient noise, because of the assumption, that the inherent noises of the two microwires are uncorrelated

$$
\operatorname{cov}\left(X^{+} Y^{+}\right)=\sigma_{X+Y+}=\frac{1}{N} \sum_{i=1}^{N}\left(x_{i}^{+}-\bar{X}^{+}\right)\left(y_{i}^{+}-\bar{Y}^{+}\right) \text {. }
$$

The standard deviation of the inherent noise of microwire in channel $X^{+}$is then given by

$$
\sigma\left(H_{S W}\right)=\sqrt{\sigma_{X^{+}}^{2}-\sigma_{X^{+} Y^{+}}} .
$$

Experimental results collected by presented method are shown in Fig. 3. In this measurement $H_{M A X}$ was set to $300 \mathrm{~A} / \mathrm{m}, T$ was $1 \mathrm{~ms}$ and $N$ was equal to 1000 samples. The microwires had chemical composition of $\mathrm{Fe}_{38.5} \mathrm{Ni}_{39} \mathrm{Si}_{7.5} \mathrm{~B}_{15}$, had length of $2 \mathrm{~cm}$ and were placed at the distance of $2 \mathrm{~cm}$. Mean value of $H_{S W}$ of the $X$ wire was $96.75 \mathrm{~A} / \mathrm{m}$. Whole measurement was realized by computer controlled system based on CPLD time measuring device with resolution of $10 \mathrm{~ns}$.

\section{Conclusion}

The method presented in this article has successfully shown the possibility of noise decomposition into the inherent noise of $H_{S W}$ and the ambient noise. Inherent noise is a critical parameter of magnetic materials used as sensors. The method could be used in noisy laboratory environment without need of an expensive shielding chamber.

The suppression of ambient noise, and subsequently the much more precise and stable measurement of the inherent noise of microwire switching field is evident in Fig. 3. The corrected value of $H_{S W}$ mean standard deviation was $1.14 \mathrm{~A} / \mathrm{m}$ while the uncorrected mean standard deviation was $1.63 \mathrm{~A} / \mathrm{m}$. Corrected data was also more stationary in comparison to uncorrected once.

Precise specification of microwire noise is important for further applications. Decreasing of noise improves the precision, extends the frequency range and subsequently, the range of applications.

\section{Acknowledgments}

This work was supported by Slovak Research and Development Agency under contract No. APVV-0266-10 and Scientific Grant Agency of the MESRaS SR and SAS under contract No. VEGA 1/0286/13.

\section{References}

[1] D. Praslička, J. Blažek, M. Šmelko, J. Hudák, A. Cverha, I. Mikita, R. Varga, A. Zhukov, Transactions on Magnetics 49, 128 (2012).

[2] D. Praslicka, J. Blazek, M. Smelko, J. Hudak, I. Mikita, R. Varga, A. Zhukov, IC-MAST 2012, Abstracts book, p. 139, (2012). 